\title{
Active accessibility: A review of operational measures of walking and cycling accessibility
}

\author{
David S. Vale \\ University of Lisbon \\ dvale@fa.ulisboa.pt
}

\section{Mauro Pereira}

\author{
University of Lisbon \\ mauro.pereira@fa.ulisboa.pt
}

\author{
Miguel Saraiva \\ University of Lisbon \\ miguelsaraiva@fa.ulisboa.pt
}

\begin{abstract}
Active travel is enthusiastically promoted in the Western world due to its clear and demonstrated individual and collective benefits. While active travel has been shown to be associated with features of the built environment such as density and land-use mix, it is also associated with walking and cycling accessibility-which we designate as active accessibility. However, the measurement of active accessibility is not straightforward and it can represent significantly different features of the built environment. This paper presents an extensive review of published research that measures active accessibility. We classified the literature into four categories based on the methodology used: distance-based, gravity-based or potential, topological or infrastructure-based, and walkability and walk score-type measures. A fifth category was created to classify outliers consisting of distinct methodological approaches or hybrids of the four main categories. We argue that almost all of these methods have conceptual and computational limitations, and that there are inconsistencies in the use of concepts and terms. Furthermore, no sensitivity analysis was carried out on the selected parameters. We conclude by presenting some guidelines that might improve the value and clarity of active accessibility research, theory, and practice.
\end{abstract}

Keywords: Accessibility, active travel, walking, cycling, non-motorized accessibility, pedestrian accessibility, bicycle accessibility, walkability, bikeability

\section{Introduction}

Active travel, i.e., walking and cycling, is enthusiastically promoted in the Western world. These travel modes have clear and demonstrated individual as well as collective benefits, which encompass climate

Copyright 2015 David S. Vale, Miguel Saraiva, and Mauro Pereira

http://dx.doi.org/10.5198/jtlu.2015.593

ISSN: 1938-7849 | Licensed under the Creative Commons Attribution - Noncommercial License 3.0

The Journal of Transport and Land Use is the official journal of the World Society for Transport and Land Use (WSTLUR) and is published and sponsored by the University of Minnesota Center for Transportation Studies. This paper is also published with sponsorship from WSTLUR and the Institutes of Transportation Studies at University of California, Davis and University of California, Berkeley. 
change mitigation, pollution and noise reduction, urban vitality, public health, obesity, not to mention the individual and collective financial benefits. One of the ways in which active travel is promoted is by altering the characteristics of the built environment in which the individuals live and move, as it has been shown that the built environment has a clear influence on travel behavior and active travel in particular (Handy et al. 2002; Forsyth et al. 2008; Brownson et al. 2009).

One important aspect of the built environment is accessibility. Accessibility can be defined as the ability to reach relevant activities, individuals or opportunities, which might require traveling to the place where those opportunities are located (Handy 2005). There are two main approaches to measuring accessibility: place-based, which is focused on the physical separation of key locations for individuals; and individual-based, which is focused on the space-time restrictions of individuals themselves (Horner 2004). These two approaches are intimately related as in place-based accessibility, locations represent clusters of entities and/or actors, and accessibility reflects an individual's potential space-time prism when the individual is in that location (Harris 2001; Vale 2010). Therefore, from both perspectives, accessibility is determined by the spatial distribution of destinations, the ease of reaching them, and the quality and character of the activities found at the destinations (Handy and Niemeier 1997). In this paper, we adopt the meaning of "the ability to reach relevant activities, individuals or opportunities," which necessarily requires traveling from the place where accessibility is being measured to the place in which opportunities are located. We are therefore focusing our analysis in place-based accessibility.

Methodologically, there are three main approaches to measuring place-based accessibility: infrastructure-based measures, activity-based measures, and utility-based measures (Geurs and van Eck 2001; Halden et al. 2000; Kwan 1998). Infrastructure-based measures are based exclusively on features of the street and transportation network and are insensitive to the location of activities in space. Activity-based measures (also designated gravity-based or Hansen-type measures) are based on the gravity model and weight opportunities according to a travel impedance function. The accessibility of a place is therefore assessed as the combined effect of the size of opportunities and the cost of traveling to them. Finally, utility-based measures (also designated benefit measures) are developed from microeconomic random utility theory, and describe accessibility as the result of a (rational) choice from a set of destinationtransportation alternatives.

Nowadays, information and communication technologies (ICT) have transformed space-time, allowing several activities to be performed asynchronously and/or remotely. However, the relationship between ICT, accessibility and travel is extremely complex and they can both substitute and complement each other (Miller 2005). As Tobler's first law of geography states, "everything is related to everything else, but near things are more related than distant things" (Tobler 1970, p. 236); consequently spatial accessibility remains an important feature of space, reflecting the ease of reaching opportunities.

In this paper, we restrict our analysis to accessibility by active travel. Several terms have been used in literature to express this concept, including walking accessibility, pedestrian accessibility, non-motorized accessibility, walkability, bicycle accessibility, and bikeability. Although non-motorized accessibility is often used to designate walking and cycling, it is being replaced by active travel or human-powered transportation. This is because these modes are associated with the concept of physical activity, which is defined by the World Health Organization as "any bodily movement produced by skeletal muscles that requires energy expenditure," and includes walking, cycling, and participating in sports. Therefore, in line with these concepts, here we adopt the term "active accessibility," to express accessibility by active travel, i.e., accessibility by walking and cycling.

Although active accessibility is easy to understand and explain it is inconsistently measured. It has been measured at different scales, with different variables, methods and strategies. There is therefore a risk that the same concept may represent different phenomena. In this paper, we review objective active 
accessibility measures, and deliberately exclude perceived accessibility measures. Thus, it is a methodological review of active accessibility measures that can be applied in a variety of urban contexts. Although there are other reviews of accessibility measures (Geurs and Van Wee 2004; Iacono, Krizek, and El-Geneidy 2010; Maghelal and Capp 2011; Talen and Koschinsky 2013), this analysis fills a gap in the literature as it focuses exclusively on active accessibility and operational measures that can be reproduced in different contexts. In this sense it provides a categorized portfolio of current active accessibility measures. Moreover, we provide a theoretical-methodological evaluation framework that makes explicit the implicit assumptions in each measure, thereby improving the clarity of the evaluation.

This paper is organized as follows. In the next section we briefly discuss the relationship between the built environment and active travel, and the relationship with active accessibility. Then we present the methodology used to identify, collect, and classify published research on operational active accessibility measures. In Section 4 we present and describe the literature included in the review, which is divided into four main categories. The paper finishes with a discussion of the theoretical and practical aspects of our research, the advantages and limitations of our methodologies, and some proposals to improve the measurement of active accessibility.

\section{The built enviroment, active travel, and accessibility}

The Behavioral Model of the Environment (Lee and Moudon 2004; Moudon and Lee 2003) provides a theoretical and conceptual framework for the way in which the built environment relates to mobility and shapes accessibility. This model takes a socio-ecological perspective, and emphasizes that not only socio-cultural factors but also physical environmental factors are important to change and explain behavior. The model is composed of three environmental components: the origins and destinations of trips, route characteristics of trips, and the characteristics of the area around origins and destinations. The variables that are used to measure these three components are not mutually exclusive, as many address more than one component. Accessibility is one example: In order to measure the accessibility of an origin with respect to one or more destinations two components are simultaneously evaluated, namely origins and destinations and route characteristics. It could even be argued that accessibility is a three-component variable, as the characteristics of the area around origins and destinations are also often used as parameters in accessibility indicators. Examples include topological measures, which focus on the characteristics of the network around origins and destinations, and therefore implicitly reveal the characteristics of an area around the measurement point.

In the last decade there have been several reviews in the travel-behavior and public-health literature of the relationship between the built environment and active travel or physical activity that focus on some or all of these three components (Forsyth et al. 2007; Forsyth et al. 2008; Lee and Moudon 2006; Pikora et al. 2003; Saelens and Handy 2008; Saelens, Sallis, and Frank 2003; Talen and Koschinsky 2013; Handy et al. 2002; Brownson et al. 2009; Ewing and Handy 2009). Although most of these studies are focused on North American and Australian cities, the findings provide a valuable and suitable framework for the evaluation of other urban situations. It is often the case that a range of objective variables is used to analyze and characterize the built environment, and they can be used to measure the same characteristic in a variety of ways. They can be grouped into six influential environmental factors: density (residential, employment, or both), diversity (land-use mix and destinations), distance (proximity or accessibility), route characteristics (street connectivity and quality of the infrastructure), safety (both personal and from traffic), and aesthetic qualities (trees, parks and open spaces, bus shelters, etc.). Topography (slope) is almost exclusively referenced in cycling travel research (Pikora et al. 2003; Saelens, Sallis, and Frank 2003). Different domains of physical activity may be related to different features of the built environment. For instance, leisure-time physical activity tends to be associated with access to 
recreation facilities, while transportation physical activity tends to be associated with access to destinations and infrastructure in general.

Whatever the motivation, the active travel trip is important in itself (Handy et al. 2002) due to the personal benefits that are derived from walking or cycling. Walking and cycling are intrinsically social activities and the pedestrian and cyclist develop a particular relationship with the built environment. This translates into other characteristics of the built environment such as aesthetics, safety and security, comfort, and also urban design qualities such as imageability, enclosure, human scale, transparency and complexity (Ewing and Handy 2009). These characteristics can become as important as density, landuse diversity, or street connectivity in explaining active travel behavior.

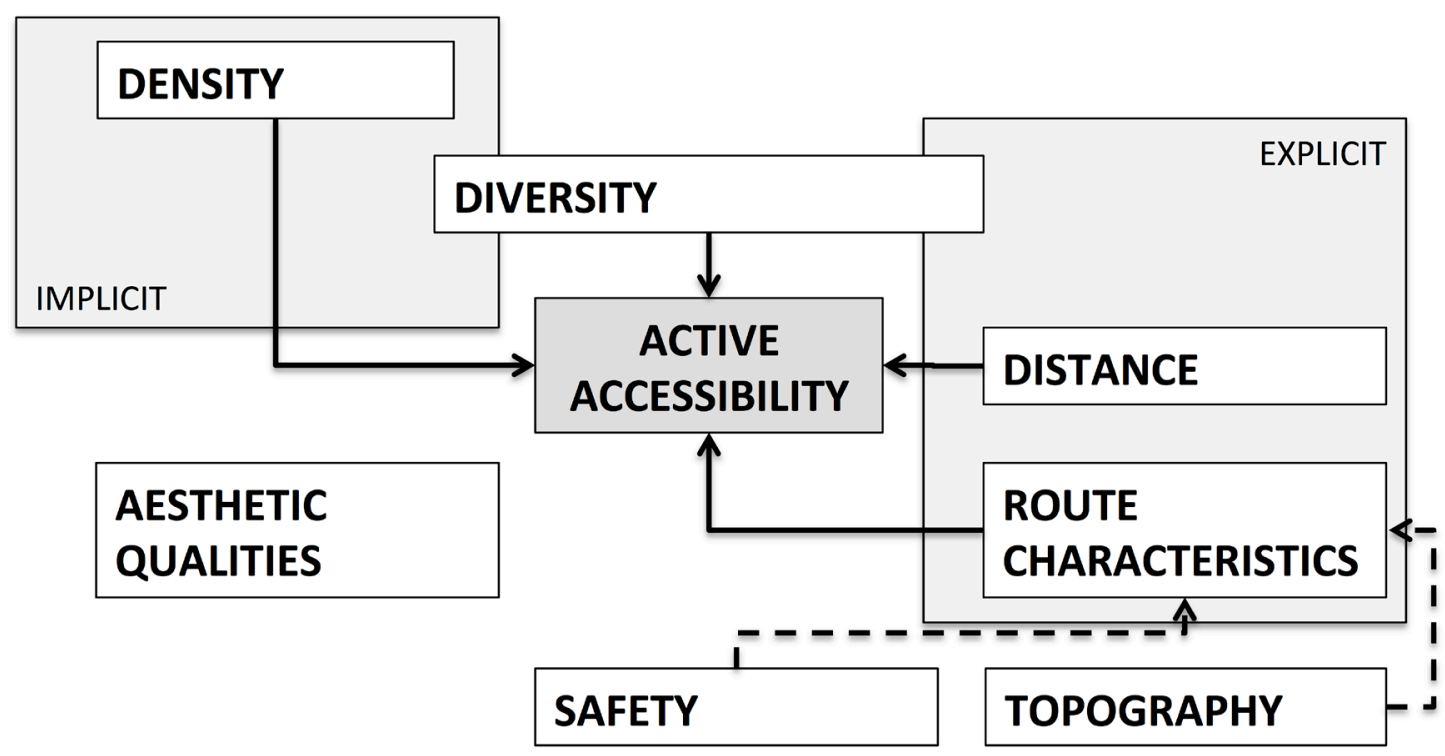

Figure 1: Relationship between built environment factors and active accessibility

Active accessibility is either implicitly or explicitly included in the measurement of the built environment (Figure 1). In practice, density is often used as an implicit proxy for overall accessibility, as denser places have more facilities and opportunities nearby. Likewise, the distance to the closest facility is an explicit measurement of accessibility. Route characteristics such as street connectivity are other explicit accessibility measures, while infrastructure quality has a clear impact on accessibility. Diversity (measured by indicators such as land-use mix) implicitly measures accessibility, because a place with a greater mix of land-use facilitates access to a broader range of opportunities or facilities. Diversity (measured by indicators such as intensity) can also be an explicit measure of accessibility, as it measures the number of facilities in the surrounding area. Therefore, accessibility cannot be separated from the built environment, as several of the physical features of the built environment are closely linked with, and influence accessibility.

Likewise, there is typically high collinearity between the physical features that make up the built environment, which are normally used to measure its quality. A clear example is the walkability concept (Frank et al. 2005; Frank et al. 2006), which is a composite index of several built environment variables. Walkability reflects both the potential of a space to be walkable and the ability to access facilities on foot. Finally, the creation of a spatial threshold around an origin or destination in order to measure its walking or cycling potential implicitly measures accessibility, because the boundary itself is a measure of impedance of access to certain opportunities. 
Active accessibility, therefore, can be defined as the ability of an individual to reach relevant activities by active travel alone. It can be either a place-based or an individual-based measure, and the special needs of older people, children, disabled people, and other groups can be taken into consideration. It involves the analysis of walking and cycling infrastructure and the calculation of available routes (see, for instance, Church and Marston 2003; Dong et al. 2006; Achuthan, Titheridge, and Mackett 2010).

An important and often disregarded issue when measuring the built environment is the modifiable area unit problem, which translates into arbitrarily defined boundaries and has two impacts: a scale effect (the spatial resolution), and a zoning effect (the configuration of the spatial units) (Clark and Scott 2013; Brownson et al. 2009). Indeed, apparently simple measures such as density can assume different values when measured at different spatial scales and with different spatial units (Forsyth et al. 2007). Another limitation of most early research is that it mainly focuses on the features of the built environment around the home, as it assumes that the active trip begins at home. However, the actual travel pattern of the population is becoming increasingly complex, and consequently the characteristics of the built environment around the workplace (for instance) can be as important in explaining travel behavior and modal choice. Finally, other variables that have been found to be relevant to explain travel behavior, such as parking availability and cost (Hess 2001; Vale 2013) are largely ignored in the active travel literature (Bradshaw 1993 is an exception). However, they may be extremely important in explaining active travel behavior, as they may decrease the utility of car travel, and therefore contribute to an increase in walking and cycling.

\section{$3 \quad$ Methodology}

In September 2013, we carried out a systematic literature review of papers written in English and published in peer-reviewed journals and conference proceedings. Our research tools included ScienceDirect, the Web of Science ${ }^{\mathrm{TM}}$, the Transportation Research Board's Transport Research International Documentation (TRID) database and Google Scholar. We used the following keywords: walking accessibility, pedestrian accessibility, bicycle accessibility, cycling accessibility, non-motorized accessibility, walkability, and bikeability. We also included a recently published report from a European research project that identifies accessibility instruments and methods that can be used as planning tools (Hull, Silva, and Bertolini 2012), from which we selected methods that discuss walking or cycling. Other reviews were included in order to validate our research and identify other relevant methodologies (Geurs and Van Wee 2004; Iacono, Krizek, and El-Geneidy 2010; Maghelal and Capp 2011; Talen and Koschinsky 2013). From the papers that were identified, only those that explicitly measured accessibility through the physical aspects of the built environment were selected, which led to a total of 84 papers. In terms of mode of travel, these papers can be classified into four major groups (literature reviews excluded): walking, bicycling, active travel, and public transport and active travel. Walking accessibility made up the largest group (32 papers), followed by public transport and active travel ( 25 papers), active travel alone (16 papers), and bicycle accessibility (6 papers).

Following the work of Handy and Niemeier (1997) and Miller (2005), we developed a theoreticalmethodological evaluation framework in order to review and classify in detail the active accessibility methodologies we found (see Table 1). This evaluation framework is based on the whole range of specification issues that the researcher must consider when designing his or her accessibility measurement method. It should be noted that two issues were not included in the analysis: socioeconomic disaggregation and temporal disaggregation. This was because almost none of the identified accessibility measures took them into account (Horacek et al. 2012, for example, is an exception). 
Table 1: Specification issues used to evaluate accessibility measures

\begin{tabular}{|c|c|c|}
\hline \multicolumn{2}{|c|}{ Specification issue } & Summary/key questions \\
\hline \multirow{5}{*}{ Disaggregation } & Spatial & Which spatial units are being used (spatial resolution)? \\
\hline & Socio-economic & $\begin{array}{l}\text { Distinguish different socio-economic groups, reflecting differ- } \\
\text { ent needs and constraints }\end{array}$ \\
\hline & Trip purpose & Work and/or non-work trips \\
\hline & Transportation mode & $\begin{array}{l}\text { Walk, Cycle, Active Modes (Walk and Cycle), Active Modes } \\
\text { and Public Transport }\end{array}$ \\
\hline & Temporal & $\begin{array}{l}\text { Different times of the day (peak versus off-peak travel / avail- } \\
\text { ability of opportunities) }\end{array}$ \\
\hline \multirow{2}{*}{$\begin{array}{l}\text { Places of reference (origins and } \\
\text { destinations }\end{array}$} & \multicolumn{2}{|c|}{ Origin-based and/or destination-based measures? } \\
\hline & \multicolumn{2}{|c|}{$\begin{array}{l}\text { Which places (related to trip purpose) are considered destinations / what opportunities } \\
\text { are being considered? }\end{array}$} \\
\hline \multirow[t]{2}{*}{ Attractiveness of opportunities } & \multicolumn{2}{|c|}{$\begin{array}{l}\text { How to measure opportunities (binary, count number for aggregate destination, square } \\
\text { footage, etc.)? }\end{array}$} \\
\hline & \multicolumn{2}{|c|}{ Travel distance, time, cost or combination of them? } \\
\hline \multirow[b]{2}{*}{ Travel impedance } & \multicolumn{2}{|c|}{ How to measure travel impedance (Euclidean, Manhattan, network distances)? } \\
\hline & \multicolumn{2}{|c|}{$\begin{array}{l}\text { Which impedance function (inverse power, negative exponential, modified Gaussian, } \\
\text { cumulative opportunities), and how to calibrate its parameters? }\end{array}$} \\
\hline
\end{tabular}

Several of the accessibility measures we identified had other specificities that could not be included or evaluated within our initial theoretical framework. These measures did not strictly relate to accessibility and often included it in a broader built environment evaluation based on a common framework. Examples include: land-use mix, density (residential population and employment) and safety, together with the infrastructure characteristics of networks such as intersection density or count, node/link ratio, block length, and sidewalk continuity and quality. Other important characteristics of the built environment, such as slope and parking, were mentioned in some studies. We therefore complemented the initial evaluation framework presented above with a description of the built environment features included in each methodology.

\section{$4 \quad$ Active accessibility: methodological review}

Authors agree on the definition of four major categories of place-based accessibility measures: (i) activitybased, which can include gravity-based (also designated attraction-accessibility or potential) and cumulative opportunities measures (also referred to as isochrone or contour measures); (ii) topology-based, which include topological measures of the network; (iii) distance-based, which include analyses of the closest facilities, and (iv) utility-based, also referred to as benefits measures (Handy and Clifton 2001; Church and Marston 2003; Dong et al. 2006; Vale 2010; El-Geneidy and Levinson 2011). Using these four major types we categorized active accessibility studies based on their methodological and computational similarities. This led to an immediate, major decision, namely to exclude utility-based measures. These measures are based on concepts of rational behavior and utility maximization, and describe accessibility as the result of a (rational) choice from a set of destination-transportation alternatives. The existence of a random component, which assumes that not all individuals in the same location have the same accessibility to the same opportunities, and which needs to be based on prior surveys, and the inherent difficulty in interpreting, explaining, and comparing these measures, led them to be excluded from this review. We also noted that, in the case of pedestrian accessibility, a fifth category of measures 
could be identified. As no definition exists, we designated them as "walkability" or "walk score-type" measures. They are related to two well-known and popular methodologies, which combine some of the accessibility measures previously mentioned and others that include land-use/built-environment measures.

The result of our analysis of over 80 accessibility measures led to a grouping into four, slightly rearranged, categories, namely: (i) distance-based; (ii) gravity-based; (iii) topological or infrastructure-based; and (iv) walkability or walk score-type. These categories, their respective subdivisions, and the methodologies contained therein are summarized in Figure 2. The following sections provide a brief description of each category, the variables used, accessibility algorithms, and the studies that contributed to their definition. We also identify small differences between methodologies included in the same category, group or type. Around 10 methodologies could not be grouped, as they proved to be special cases, combinations of the other four categories, or distinct methodologies that included relevant keywords in the title. An example is "walk score," used in the eco-friendly walk score developed by Lwin and Murayama (2011). These methodologies are briefly described in section 4.5.

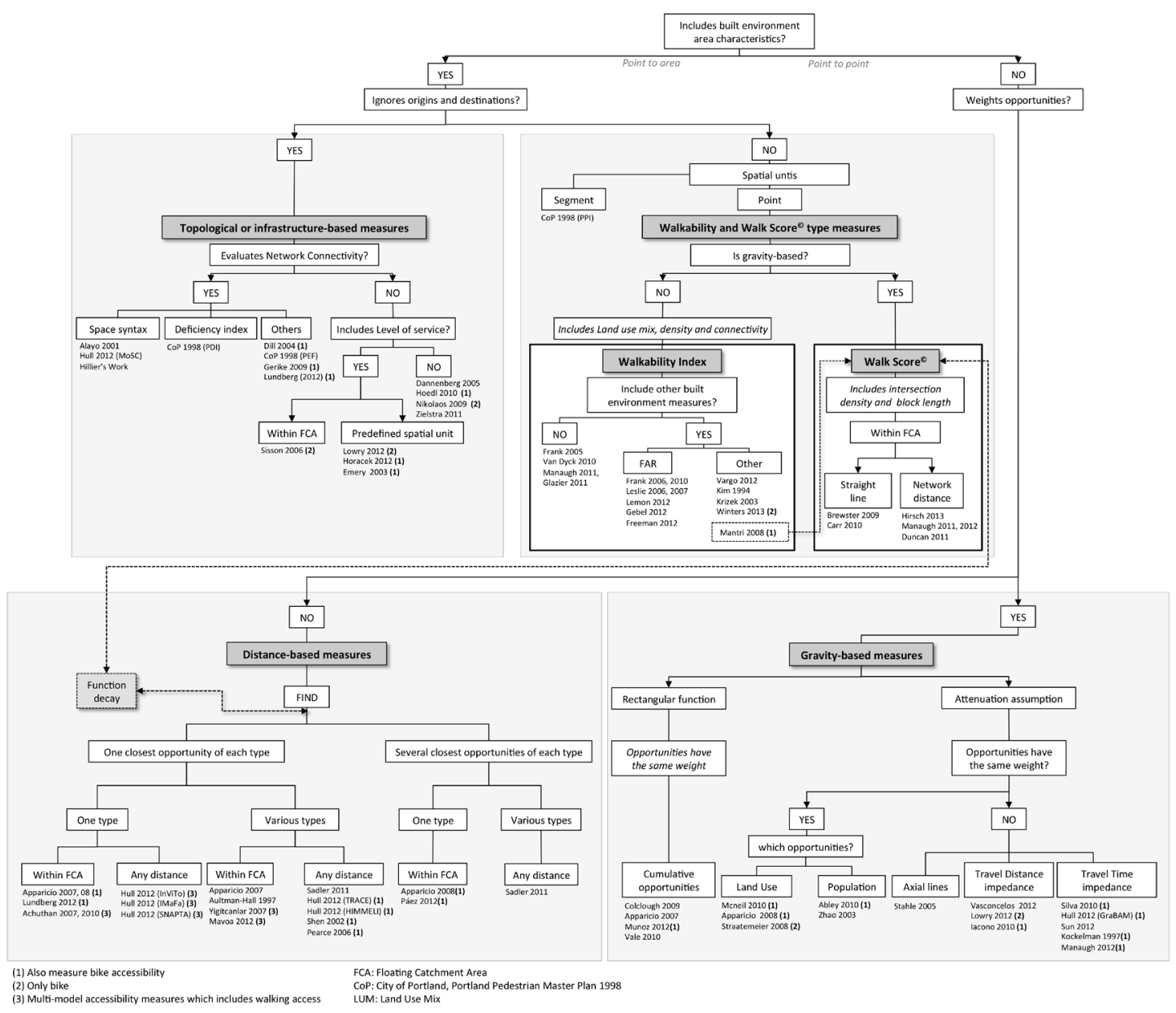

Figure 2: Methodological evaluation and classification of active accessibility measures 
It could be argued that these four accessibility measurement categories serve distinct purposes. Distancebased measures are useful if opportunities are seen as perfect, or near-perfect, substitutes. Examples are accessibility to emergency services, bus stops, or supermarkets, where it is assumed that an individual wants to access the closest possible opportunity, and all opportunities provide the same benefit. Gravitybased measures (including cumulative opportunities measures) are useful if opportunities are seen as complementary, and travel (time or distance) is seen as a cost to be minimized or kept within a certain acceptable value. Examples are accessibility to jobs, other residents, commerce and services, or public parks, where more is better, and being closer represents higher accessibility. Topological accessibility measures can be used to analyze the impact the road network has on movements and therefore overall accessibility. Although these measures do not evaluate existing opportunities, they can be very useful as planning tools — either to identify intervention priorities — or to identify the potential impacts of urban development proposals. Finally, walkability (including bikeability) measures are useful as overall indicators of the active travel conditions in spaces, and are very popular in the health literature as explanatory variables for the health of residents.

\subsection{Distance-based accessibility measures}

Distance-based accessibility measures consider accessibility simply as a function of the spatial separation between places, i.e., accessibility is a synonym of proximity, and therefore higher separation implies lower accessibility. Apparicio et al (2008) defines four categories of accessibility: 1) distance to the closest opportunity; 2) the number of opportunities within n meters or minutes; 3 ) the mean distance to all opportunities; and 4) the mean distance to the n closest opportunities. However, we argue that cumulative opportunities measures, which have as output the number of opportunities, should be regarded as a particular case of gravity-based or potential measures, in which the impedance function of equation (1) is rectangular ${ }^{1}$ (see below). They are therefore discussed in the next section.

It should be noted that distance-based accessibility measures are extremely sensitive to the way in which travel impedance (i.e., distance) is measured. Accordingly, four types of distance can be identified: Euclidean distance, Manhattan distance, shortest network distance, and shortest network time. Only one article in this category used "straight line" distance (Shen 2002), although it should be noted that it was one of the oldest articles included in the review. Additionally, for a pedestrian the shortest network distance and shortest network time are normally the same, as the travel speed of the walker is similar across all street segments. However, for a cyclist, the shortest network time route can be completely different from the route that has the shortest network distance, as the cyclist often chooses the flattest route to reduce his or her physical effort. Even for a pedestrian, a significant slope can considerably reduce travel speed and/or affect the choice of route. Here again, the shortest network time route may be different to the route that has the shortest network distance. None of the methodologies included in this category specifically addressed bicycle use, but instead included walking measures that were applied to cycling, while only Pearce, Witten, and Bartle (2006) considered slope.

Within this category, we identified two subgroups (Table 2). The first calculates the distance to the single closest opportunity of each type (18 papers). The second is more rare ( 3 papers) and is based on a calculation of the distance to several closest opportunities of each type. Both of these subgroups can again be divided into methodologies that measure only one opportunity type (the closest or the n closest supermarkets, for example) and those which measure several opportunity types (the closest or the n closest supermarkets, banks, bakeries, and so on). The final division identifies methodologies that are based on a floating catchment area (FCA) and those that find the closest opportunity, regardless of distance.

Beginning with the group of methodologies where accessibility is represented by a single distance measurement from one point to the closest pre-defined opportunity, we found seven papers. Lundberg

${ }^{1}$ This function has a value of 1 between $[0, \mathrm{x}]$ and a value of 0 between $[\mathrm{x}, \infty]$ 
(2012) examined the shortest distance between home and a university campus, while Apparicio and colleagues (Apparicio et al. 2008; Apparicio, Cloutier, and Shearmur 2007) considered, respectively, the shortest distance to the closest supermarket, and the closest health facility. The latter two papers test and compare several methodologies and use several maximum distance values. Apparicio, Cloutier, and Shearmur (2007) calculated the single shortest distance to three different supermarkets (i.e., several opportunity types) and counted homes within a given buffer (a cumulative opportunities measure, see below), while Apparicio et al. (2008) calculated the distance to the three, the five and all closest health facilities (several closest opportunities of one type), counted health facilities within a given buffer and examined a gravity-based measure (see also the following section). All of the other methodologies in this group measured accessibility as the distance (generally measured by travel time) to reach a transit station (the opportunity), or from a transit station to a final destination. However, this only represents a part of the public transport trip and the measurement of the entire trip is beyond the scope of this paper; here we only look at walking access to and from stops. The AMELIA, InVito and SNAPTA methodologies assess the cost of reaching a transit stop on foot (only AMELIA uses a floating catchment area and distance as an impedance unit), while IMaFA assesses the cost (in time) of walking from a transit stop to the final destination (Achuthan, Titheridge, and Mackett 2007, 2010; Hull, Silva, and Bertolini 2012).

The work of Yigitcanlar et al. (2007) and Mavoa et al. (2012) presents broader methods that take into account multi-modal transportation. They include walking as a way to access a transit station within a floating catchment area, measured by travel time. However, these studies evaluate multiple opportunities: 13 and 17 land-use types, respectively. Similarly, Aultman-Hall, Roorda, and Baetz (1997) calculates the shortest distance to five different destinations in a given catchment area. However, most papers that evaluate multiple opportunities are not bounded by a maximum distance. For example, accessibility is calculated as the shortest distance to each of six food stores in the study area, to 16 healthrelated destinations, to a range of commercial or service facilities (HIMMEL), a range of infrastructure (TRACE), and various community facilities (Sadler, Gilliland, and Arku 2011; Pearce, Witten, and Bartie 2006; Hull, Silva, and Bertolini 2012; Shen 2002).

As highlighted above, there are significantly fewer research methods that consider both the shortest distance to a given opportunity, and the nth closest opportunities. Apparicio et al. (2008) measured the distance to the three, the five and all the closest health facilities and Páez, Scott, and Morency (2012) measured the distance (in travel time) to all daycare facilities within a floating catchment area. Only Sadler Gilliland, and Arku (2011) measured the distance to the two and the three closest opportunities for each of six different food stores for which the closest distance had already been calculated.

It should be noted that methodologies that include a floating catchment area do not agree on the definition of its size. Values range from the classic 400 meters ( 0.25 miles) to almost 4 kilometers (2.4 miles) (Páez, Scott, and Morency 2012). Time, as an impedance unit is only considered when accessing public transport or, in Páez, Scott, and Morency (2012), accessing daycare facilities. 
Table 2: Analysis of distance-based measures

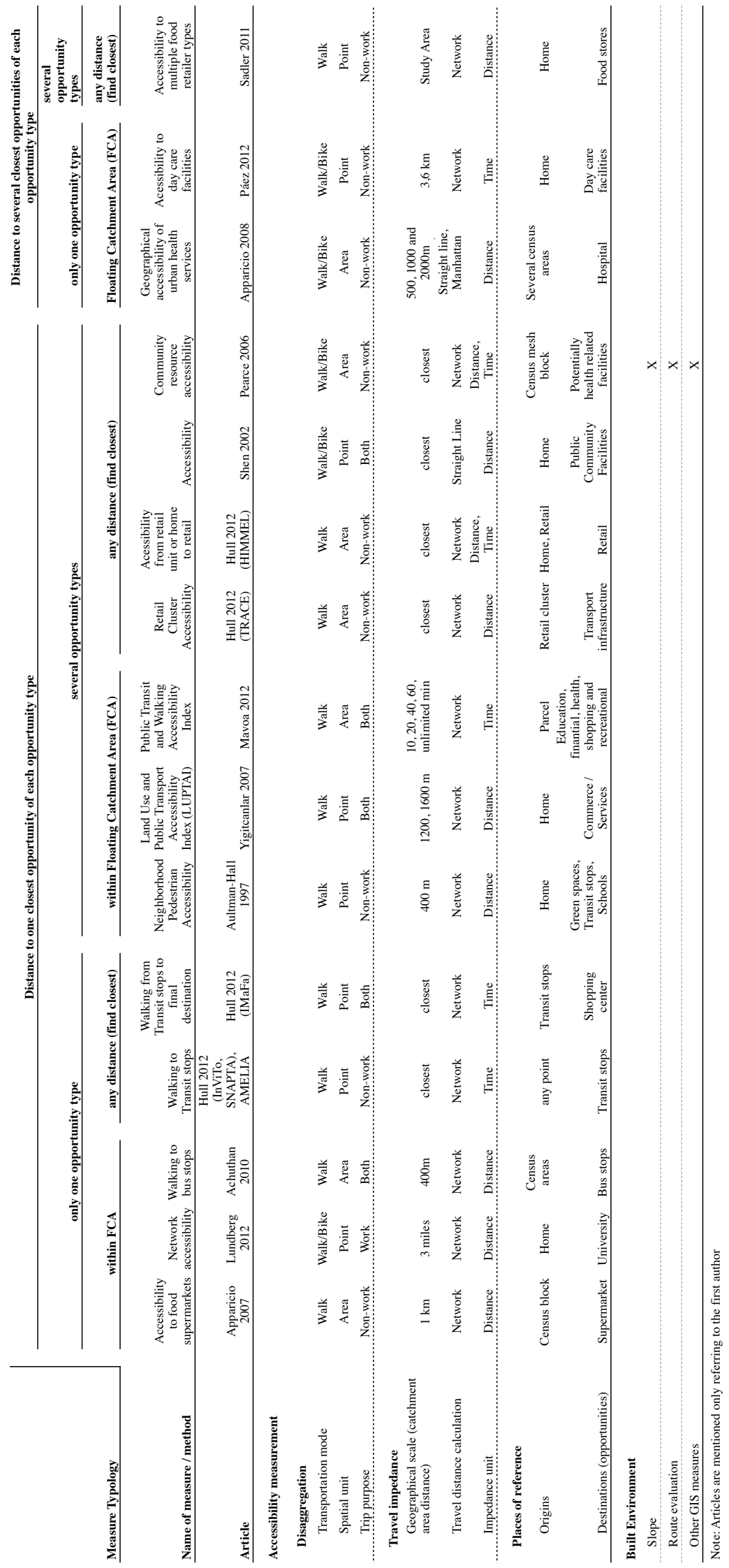




\subsection{Gravity-based of potential accessibility measures}

A important group of measures are Hansen-type (Hansen 1959), also designated as gravity-based or potential measures, which are widely used in transportation planning (Miller 2005). These are derived from the denominator in the gravity model and weight opportunities according to an impedance function, given by the following expression:

$$
A_{i}=\sum_{j} O_{j} f\left(C_{i j}\right)
$$

where $A_{i}$ is the accessibility of place $i, O_{j}$ are relevant opportunities found at $j, C_{i j}$ is the cost of traveling between $i$ and $j$, and $f\left(C_{i j}\right)$ is an impedance function that measures the spatial separation between $i$ and $j$.

When applied to active travel, the cost or traveling from i to $\mathrm{j}\left(C_{i}\right)$ is only measured for walking and/ or cycling. These measures assume that travel is a derived demand and there is a tradeoff between the benefit of the opportunity and the cost to reach it from a given origin. Therefore, the closest opportunities are more valued than opportunities located farther away, and opportunities can be distinguished depending on their size or importance. Cumulative opportunities measures are a particular case of this type, in which $f\left(C_{i j}\right)$ is a rectangular function, which takes assuming the value 1 if included in a predefined threshold and the value 0 if not.

We identified two sub-categories of methodologies depending on the impedance function used in the study (Table 2). The first sub-category consists of methodologies that assume an attenuation of distance on opportunities. It can be further divided into four types based on methodological similarities. The first consists of methods that do not distinguish opportunities, where the result is the number of opportunities weighted by their distance to the origin (Zhao et al. 2003; Apparicio et al. 2008; Straatemeier and Bertolini 2008; Abley and Consultants 2010; McNeil 2011). In the case of Zhao et al. (2003) and Abley and Consultants (2010) the opportunity is "residents," while the other methodologies consider different land-use types. The floating catchment area also varies, ranging from 500 meters to 4 kilometers ( 0.3 to 2.4 miles).

The second, third, and fourth types all give opportunities different weights (attractiveness). They are initially distinguished by the impedance unit. Most authors measure impedance by travel time (second type). In this case, accessibility reflects the attractiveness of opportunities weighted by the time needed to travel from the origin to the destination (Kockelman 1997; Silva and Pinho 2010; GraBAM in Hull, Silva, and Bertolini 2012; Manaugh and El-Geneidy 2012; Sun, Lin, and Li 2012). Nevertheless, this type is far from homogeneous in terms of the travel time threshold, which ranges from 5 to 30 minutes. Moreover, measures of the attractiveness of the destination vary considerably, ranging from a scale of values given to specific land-use types, their square footage, or the number of jobs. 
Table 3: Analysis of gravity-based or potential accessibility measures

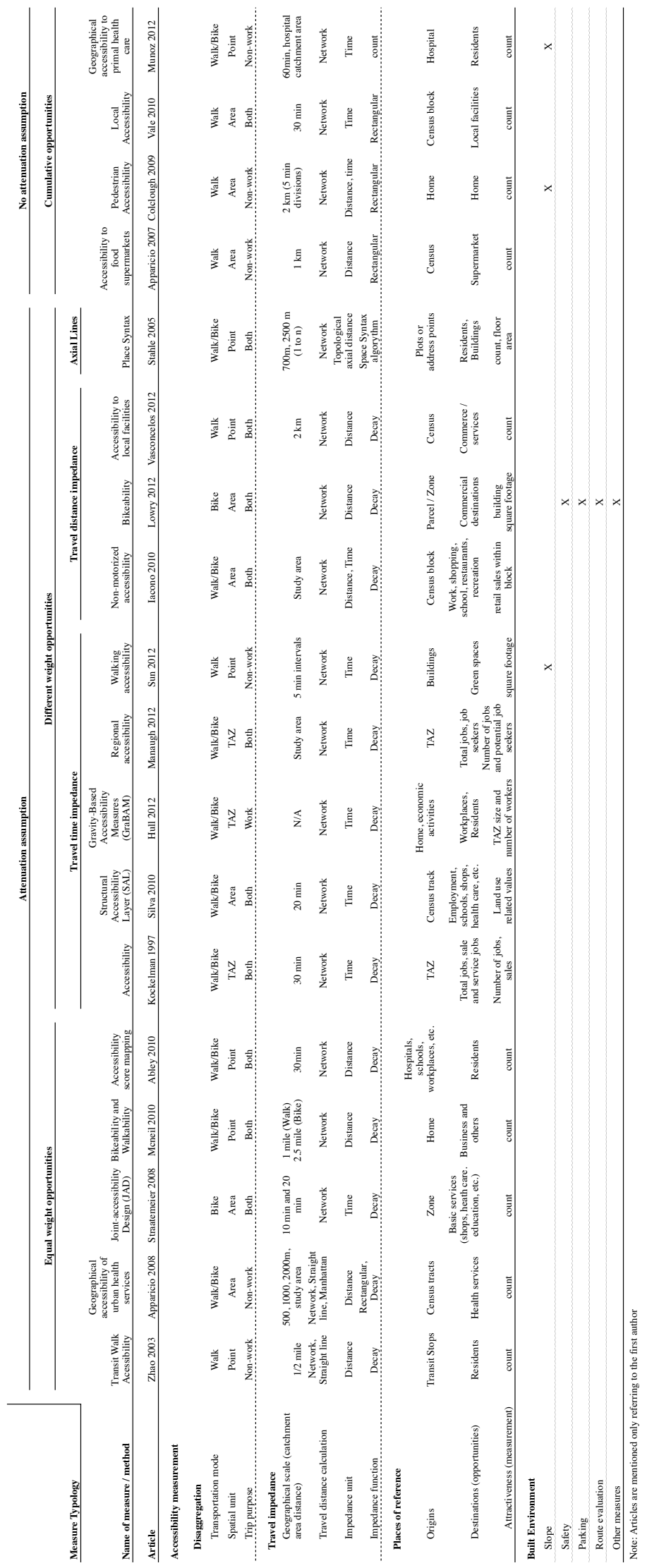


The third type is methodologically identical to the second, but in this case, travel distance, rather than travel time is used as the impedance function (Iacono, Krizek, and El-Geneidy 2010; Lowry and Callister 2012; Vasconcelos and Farias 2012). It should be noted that the Bikeability index (Lowry and Callister 2012) is the only methodology exclusively dedicated to bicycle travel. In this study, the attractiveness measure is the square footage of the building at the destination. Finally, we identified a fourth type, which contains only one method—place syntax (Ståhle, Marcus, and Karlström 2005). This uses the topological axial distance, given by the space syntax algorithm, as the impedance function, and opportunities are weighted in relation to the topological characteristics of the network. In this case, rather than the metric distance, the index reflects the "informational effort" needed to move through the urban network, emphasizing lines over points in measuring the proximity of a destination.

The second sub-category is comprised of methodologies that use a rectangular function (i.e., cumulative opportunities measures). In this case, all opportunities in the floating catchment area are given the same weight, and therefore accessibility is measured by the count of these opportunities. Apparicio, Titheridge, and Mackett (2007), Colclough (2009) and Vale (2010) take this approach, although they use a different catchment area and count different opportunities (supermarkets, homes, and local facilities, respectively). Finally, Munoz and Källestål (2012) takes a slightly different approach by first calculating travel time from all homes to a central hospital (distance-based measure). Then, it considers the hospital as the origin and counts the number of residents (based on the number of homes) served by the hospital, up to a limit of 60 minutes (i.e., the hospital catchment area).

\subsection{Topological or infrastructure-based accessibility measures}

We found several methodologies that measured accessibility based on topology (i.e., the walking and cycling accessibility of the road network). These studies take no account of origins and destinations or opportunities in the neighborhood, and instead focus on an analysis of network connectivity and/or the characteristics of the walking and cycling infrastructure. Two major subgroups were identified: those that evaluate network connectivity and those that do not (see Table 4).

Within graph theory several indicators and measures have been developed that evaluate connectivity both at the network and the node level. These include the detour index, the gamma index, the Shimbel index (also designated nodal accessibility), among others (Rodrigue, Comtois, and Slack 2013). In urban planning, however, connectivity is normally evaluated with simpler indices such as the link/ node ratio and block size (Handy, Paterson, and Butler 2003). 
Table 4: Analysis of topological or infrastructure-based measures

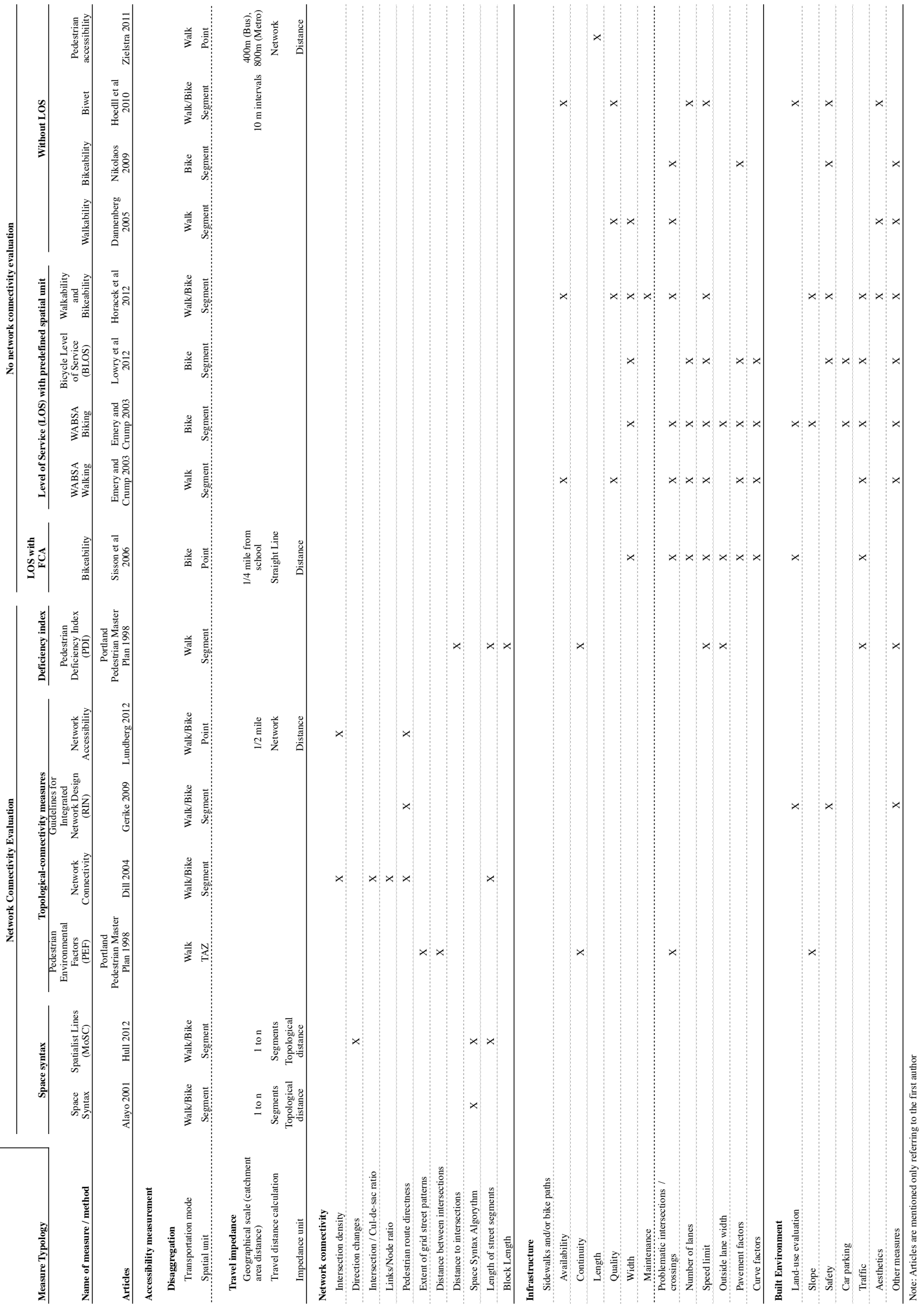


The first group (which evaluates network connectivity) concerns methods that include urban morphology parameters. This group relies on three main types of measures. The first is based on the space syntax methodology (Hillier 1996; Hillier and Hanson 1984) and is therefore closely linked to the evaluation of the relationships between segments and nodes and with the entire network (Alayo 2001; MoSC in Hull, Silva, and Bertolini 2012). The second type consists of four methodologies that emphasize connectivity. It includes two methods that combine connectivity with other characteristics of the infrastructure and the built environment such as slope, land-use evaluation or safety (City of Portland 1998; Gerike, Gerlach, and Rau 2009), while the other two (Dill 2004; Lundberg 2012) are simply connectivity measures. With the exception of RIN (Gerike, Gerlach, and Rau 2009), these methods combine several parameters in order to measure network connectivity (such as intersection density, intersection/ cul-de-sac ratio, and pedestrian route directness). The third type combines evaluations of connectivity and traffic and infrastructure, leading to the identification of a Pedestrian Deficiency Index (City of Portland 1998).

A second group of methodologies consists of topological measures that do not evaluate network connectivity, and therefore place greater emphasis on infrastructure evaluation. There are three types of measures in this group. The first contains only one method and is based on an evaluation of the level of service (LOS) within a floating catchment area (FCA) (Sisson et al. 2006). The second type is similar, but instead of a FCA, a pre-defined spatial unit is used to evaluate LOS, and the evaluation is based on the segment rather than the point (Emery and Crump 2003; Lowry and Callister 2012; Horacek et al. 2012). The third type is very different, as traffic is not considered as a relevant parameter (Dannenberg, Cramer, and Gibson 2005; Nikolaos, Athanasios, and Apostolos 2009; Hoedl, Titze, and Oja 2010; Zielstra and Hochmair 2011). Measures are based on infrastructure characteristics and the evaluation of network segments, and include parameters such as sidewalk or bike path availability, quality, and length among others.

\subsection{Walkability and walk score-type measures}

Accessibility measures classified as "walkability and walk score-type measures" include built environment characteristics in their algorithms and always express accessibility as the relationship between a point and another point or a set of points (i.e., from a clear origin to a clear set of destinations). Unlike gravity- and distance-based accessibility measures, area characteristics around these points are also taken into account in the calculation. With reference to the Behavioral Model of the Environment, it can be argued that these measures consider both origins and destinations and the characteristics of the area around them, but not route characteristics. Variables such as sidewalk quality, dropped curbs, pavement surface material, cleanliness, trees, benches, etc. play no part in these measures, and therefore they should be used with care in the evaluation of pedestrian accessibility. Bradshaw (1993)'s neighborhood walkability measure includes a series of other measures of the built environment that are not included in any other study in this group, although it only measures built environment variables and not accessibility or connectivity.

The two major groups of measures in this category follow either the work of Frank and colleagues (Frank et al. 2010; Frank et al. 2006; Frank et al. 2005) and what they call the Walkability Index, or the Walk Score approach. This is a registered methodology ${ }^{2}$ that has gained in popularity and has been used or tested since 2010. Our review identified 16 papers directly or indirectly related to the Walkability Index and six related to Walk Score (Table 5). The major difference between these approaches is that Walk Score uses a gravity-based methodology. Opportunities are weighted using a distance decay function, while the Walkability Index is based on a cumulative opportunities measure.

The Walkability Index has been used in several studies that examine the relationship between the

\footnotetext{
${ }^{2}$ http://www.walkscore.com/
} 
built environment and travel and physical activity. The term "Walkability Index" was coined by Frank et al. (2005) to express the qualities of the built environment that are associated with physical activity. The initial index consisted of three major dimensions: land-use mix, residential density, and street connectivity. These three elements, measured in a designated floating catchment area around a point (only Bradshaw 1993; Gebel et al. 2011 use a predefined spatial unit), are combined and given a z-score (according to the census tract or the neighborhood) leading to a walkability score for an area.

Prior to 2011, some authors (Van Dyck et al. 2010; Manaugh and El-Geneidy 2011) used Frank et al. (2005)'s original three-measure methodology. However, since Frank et al. (2006), the Walkability Index has included the retail floor area ratio (FAR), and network connectivity has been given twice the weight of other variables. This four-measure methodology was later used to evaluate physical activity and active transportation (Leslie, Butterworth, and Edwards 2006; Leslie et al. 2007; Frank et al. 2010) and has been used mostly ipsis verbis in more recent articles (Freeman et al. 2012; Lemon 2010). Only Glazier et al. (2012), for the three-measure index, and Gebel et al. (2011) for walkability with FAR have produced slightly altered methodologies, which have nonetheless stayed true to the walkability variable types and calculation principles.

Other authors have not replicated Frank's methodology per se, but have included the three main measures, while adding other components. Of these, the Pedestrian Potential Value (PPV) devised by Kim (1994, cited in City of Portland 1998) is worthy of note, as is the only one which pre-dates Frank et al. (2005)'s index. Kim generated an aggregated PPV for each traffic analysis zone (TAZ) within the city of Portland, using five variables (adding slope and average parcel size to the three main measures). Other studies include Vargo, Stone, and Glanz (2012)'s Google Walkability, which introduces the number of reachable transit stops and streets with sidewalks, Krizek (2003)'s neighborhood accessibility, which includes a measure of block length and uses employees as a proxy of land use, and Mantri (2008)'s walkability of a neighborhood, which uses the Walk Score land-use groups. We only found one methodology that transposed the concept of walkability to bicycle trips. The Bikeability Index described by Winters et al. (2013) includes the three basic measures, but adds the length of bicycle routes, slope, and the separation from car traffic. Each variable is given a score of 1 to 10 , which is then summed to produce the final score.

Walk Score-related articles have stayed true to the original methodology. Basically, the Walk Score index assesses the "walking potential" of a place through a combination of three elements: the shortest distance to a group of preselected destinations (such as commerce/services, green spaces, and schools), the block length, and the intersection density around the origin. It therefore links two types of accessibility: a gravity-based measure (distance accessibility), with topological accessibility (street connectivity) measured by two complementary indicators that act as penalties in the final score (linearly expanded in the range 0 to 100). We identified two types of articles. Prior to 2010, the Walk Score algorithm used a one mile Euclidean distance buffer (Brewster et al. 2009; Carr, Dunsiger, and Marcus 2010). Currently the buffer is determined by the network (Duncan et al. 2011; Manaugh and El-Geneidy 2011, 2012; Hirsch et al. 2013). All of these more recent articles cite the Walk Score website as the source for their calculations. In addition, Carr, Dunsiger, and Marcus (2010) and Duncan et al. (2011) correlate their Walk Score results with other built environment measures.

Based on Winters et al. (2013)'s Bikeability score, the Walk Score website now offers a Bike Score, which measures whether a location is good for cycling on a scale of $0-100$ based on four equally weighted components: bike lanes, hills, destinations and road connectivity, and bike commuting mode share. As far as we could ascertain, to date there are no peer-reviewed papers that have applied the Bike Score. 
Table 5: Analysis of walkability and walk score-type measures

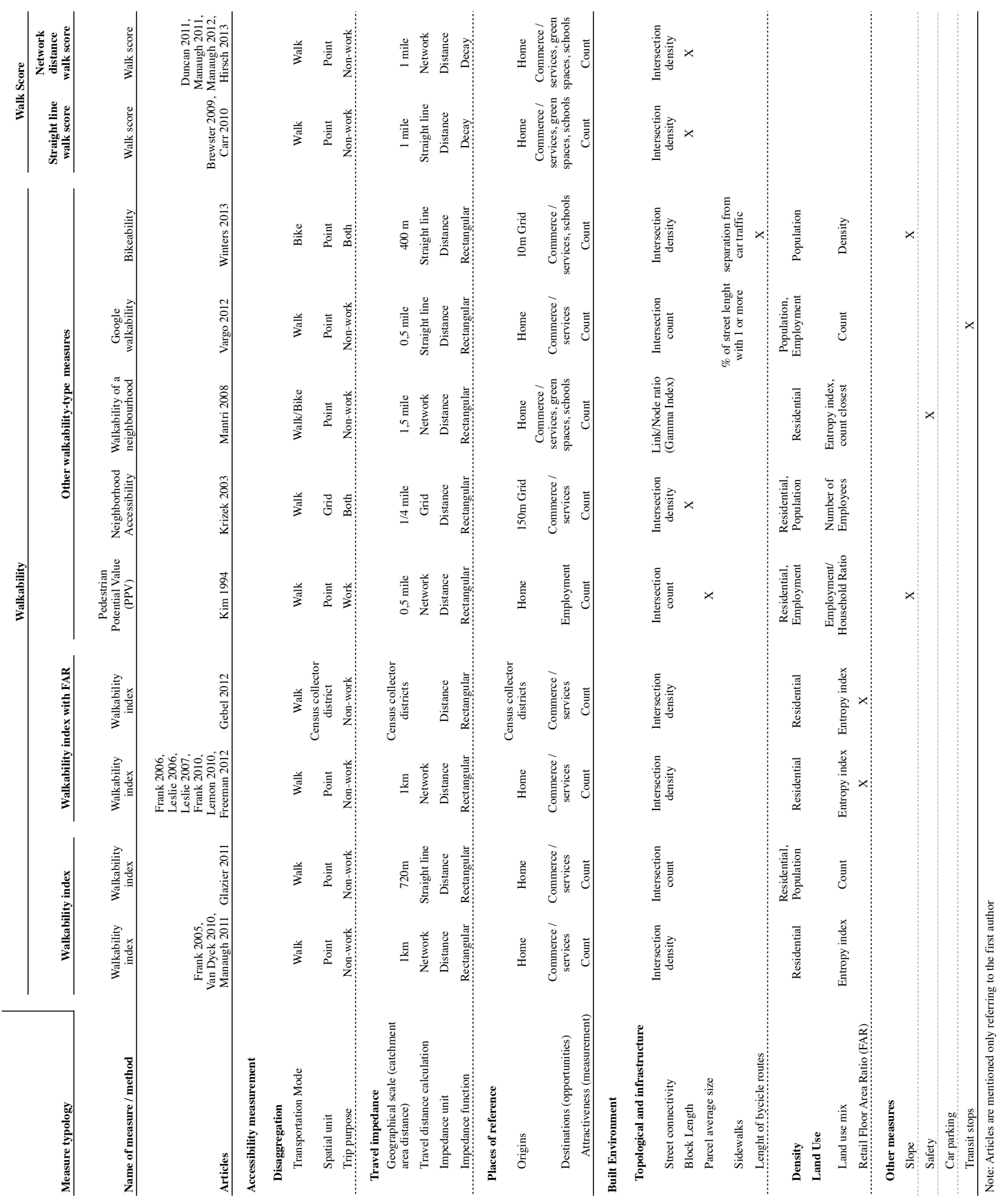




\subsection{Other active accessibility measures}

Our review uncovered around 10 methodologies for calculating accessibility that could not be included in any of our four main categories as they proved to be special cases, combinations of the other four categories, or are other methodologies with titles that contain similar terms. Only one of these methodologies is shown in Figure 2: the Pedestrian Potential Index (PPI) that was developed for Portland's Masterplan (City of Portland 1998). The PPI is mostly a topological measure. Like the previously mentioned Pedestrian Deficiency Index, the evaluation (a summed index) is based on the characteristics of street segments (their type, classification, location within the region and environmental score). However, the PPI includes another important element; segments are given more points if they are within a floating catchment area (for different radii) of schools, public parks, transit stops and pedestrian-friendly commercial spaces. In other words, it is a topological measure that includes origins and destinations, in which the spatial unit is the segment.

Two other methodologies were identified, which measured the area covered by the opportunities in the floating catchment area of a given point; the first area is divided by the second to produce a ratio. In their eco-friendly walk score calculation (Lwin and Murayama 2011), opportunities are green spaces inside the floating catchment area, while in the School Specific Walkability Index (Giles-Corti et al. 2011) opportunities are pedestrian areas. In this case, the ratio is converted from a scale of 1 to 10 , and another score is given according to a ratio that measures the proportion of main roads, to produce a final score that ranges from 2 to 20 . The use of the terms walk score and walkability index is particularly revealing, as these methodologies have little in common with their original namesakes described in the previous section. Indeed, these examples show that there is still some confusion in cataloguing and unequivocally defining active accessibility measures.

Sakkas et al. (2006) calculated the accessibility of buildings as the distance between a point outside the building (for example, the parking lot) to a given point inside it. In theory this is a distance-based measure, but the study weighted it both by a decay parameter that included slope (gravity-based) and the quality of the path (topology-based). This spatially focused accessibility measure only applies to relatively short distances, and in this case, the destination is not the building as a whole (generally represented by the centroid) but a precise location inside it. Therefore, this measure is not universal. Church and Marston (2003) include this specificity in its methodology, which can be applied to any accessibility calculation. In the study method, the relative accessibility of a given location to a person with a physical disability (whether inside a building or not) is given by the ratio of accessibility calculated for that person and accessibility calculated for a person without a physical disability. Allan (2001) calculated a cost ratio (time or distance) measured using the network and the same cost measured as the crow flies. Although this is a measure of network connectivity, it cannot be included in topological measures, as it does not exclude the origin-destination pair.

Place-rank, which is a recent methodology developed by El-Geneidy and Levinson (2006, 2011), is a gravity-based measure that redistributes people (workers) between zones (e.g., traffic access zones) based on a weighted assessment of the zone's attraction (measured by the ratio of job opportunities and the number of workers residing in the zone) and the power of the links. The accessibility of a zone is determined by the number of people commuting into it, but each person contributes to the accessibility measure depending on the attractiveness of his or her zone of origin. The measure requires several iterations to stabilize; a calculation of the weighted sum of jobs by destination is used to rank zones. The measure requires knowledge of actual choices of origins and destinations, and therefore reflects revealed behavior, which might be different to preferred behavior (Handy and Niemeier 1997).

Finally, activity-based measures (Dong et al. 2006), perceived activity set (Le Vine et al. 2013) and space-time methodologies (Miller 1999; Miller and Wu 2000; Kim and Kwan 2003) were also briefly 
reviewed, although they are considered utility-based measures as they measure on-foot accessibility as an integral part of a person's daily routine. Nevertheless, we acknowledge that space-time methodologies have a great potential to measure active accessibility of an individual, which can be significantly different from place accessibility (Miller 2007). Activity-based measures (based on utility theory) compute an individual's expected maximum utility over the choices of all available activity patterns, and display isochrones-based maps that represent the areas that can be reached based on maximum individual utility. Methodologies that include space-time measures use similar approaches, but take into account not only the travel time needed to reach a given weighted opportunity (a measure of attraction — gravity) but also how long an individual can enjoy those facilities given their space-time constraints, i.e., a time budget based on individual schedules (Kwan and Weber 2003). Kim and Kwan (2003) considered opening hours of opportunities and the time taken to enjoy the experience. For example, while people may only need five minutes to have a cup of coffee at the nearest coffee shop, they may need an hour to visit the doctor. Finally, the perceived activity set (Le Vine et al. 2013) is a predictive model of mobility resources. It is a set of out-of-home activities that encompasses an individual's potential travel needs. The formula weights the (dis)utility of acquiring or maintaining the mobility resources they might possess and the (dis)utility of using the travel modes that enable them to access the activities in their perceived activity set.

\section{$5 \quad$ Discussion and conclusion}

In the vast majority of the Western world, finding ways to increase active travel is becoming a key objective of policies and plans. The health, environmental and even financial and psychological benefits derived from the active pursuit of walking and cycling have been continuously demonstrated, not only by theoretical scientific research, but also by practical empirical evidence. Walking and cycling are no longer merely weekend leisure activities, rather they are, or aim to be, part of day-to-day living. For this to happen, it is essential that the built environment provides suitable conditions so that they can become usual and routine. The likelihood of walking and cycling has been associated with the proximity of the destination to the home. As an example, the absence of supermarkets near residential areas and/or workplaces is expected to significantly reduce the likelihood of walking or cycling to shop for groceries. These, and other related subjects have become an increasing focus of scientific discussion since the turn of the millennium.

However, current ways to measure active travel accessibility are very diverse, and there is little agreement on theoretical and methodological concepts and assumptions. In this review, we have explicitly analyzed operational measures of walking and cycling accessibility, which can be replicated in different urban and national contexts. We found around 80 scientific papers, reports, or theses published in the last 15 years, which for the most part (with different purposes) measured a single variable: the ability of a person to reach a place by walking or cycling. In line with the concept of active travel, we suggest that the concept of active accessibility can express this particular type of accessibility.

The first and major outcome of our review confirmed our suspicions: Ways to measure active accessibility are as varied as the number of scholars that measure them. Moreover, the same concepts have different meanings and are used to describe different methodologies. The term walkability, for instance, is used as a combined land-use/accessibility index (Frank et al. 2006; Frank et al. 2005) but also as a topological index (Dannenberg, Cramer, and Gibson 2005; Horacek et al. 2012), and a walkable area ratio (Giles-Corti et al. 2011). Forsyth and Southworth (2008) expressed concern about this confusion, and it remains a major flaw in active accessibility research.

From a theoretical perspective, however, ways to measure accessibility can be grouped into categories that have been defined for decades. Regardless of the variables or the coefficients used, or the names 
given to them, methodologies still calculate accessibility on the basis of infrastructure-, gravitationalor distance-based algorithms. Our research identified a fourth group: walkability and walk score-type measures, which introduce built environment variables into a gravitational-based model. The lack of systematization is not, therefore, theoretical, but practical or methodological.

It is interesting to examine the reasons for the numerous dissimilarities between similar methodologies. A second question relates to the added value of an extra variable included in a previously tested method, which is often unclear. For example, when Frank et al. (Frank et al. 2010; Frank et al. 2006) introduced the retail floor area ratio into their earlier three-variable walkability index methodology, they were really adding another land-use variable. This new walkability index may be a better predictor of accessibility, but it may also lead to collinearity problems as the new algorithm possesses two land-use measures. Likewise, Walk Score considers both intersection density and average block length, which are two measures of street connectivity, but it ignores infrastructure features of the network such as pavement quality. Furthermore, not only do different methodologies in similar categories calculate the same variable in a different way, but this also can occur within the same methodology. For example, 11 ways were found to measure street connectivity, and the combination of variables used to measure the quality of a bicycle path seems to be endless. Therefore, the most important issue seems to be not what to measure, but how to measure. In this context, the walkability index is a paradigmatic example, as all the methodologies we reviewed included a measure of land-use mix, density, and connectivity in their algorithms, yet few calculated these three measures in exactly in the same way.

Many of these problems can be explained and justified in terms of data limitations. In all scientific research, but particularly spatial analysis, data collection is a major concern (Talen 2003), and it is often the case that the necessary data is not available. In the case of accessibility there seems to be a dichotomy between what can be obtained in the field and what can be obtained through municipal or open-source databases. In the initial stages this can limit the choice of model, for example, the non-inclusion of the time of day, detailed land-use data, or other subjective variables. This latter point is of particular interest, as utility- or survey-based measures are harder to find in the literature, partly because they require prior data collection and allocation of resources. In addition, data is collected from different sources, which makes it harder to replicate and subsequently compare models. Therefore, measures that simplify data collection and rely on pre-established networks (e.g. Open Street Map) diminish the computational effort and offer accessible and comparable planning tools. Consequently, they become more popular, despite their notable deficiencies. Walk Score for example, does not include workplaces and excludes time of day. From a time-geography perspective, it focuses almost exclusively on flexible activities and neglects fixed activities such as work, childcare, and so on. Therefore, it reflects the accessibility of activities where the individual is free to choose when and where to perform them, and not the accessibility of activities that require the individual to be present in a certain place at a certain moment in time. Another major data limitation we found is topography. In assessing the accessibility of bicycling, slope measurements should always be included, as it is known that cyclists choose routes that minimize elevation gain. Furthermore, although we would argue that slope is also important for walking, it was largely absent from the walking accessibility measures we reviewed. We believe that data limitations may justify this absence. Finally, the extensive use of road centerlines to represent the pedestrian network may increase measurement errors, by overstating real pedestrian accessibility measured by lines representing sidewalks and pedestrian crossings (Van Eggermond and Erath 2014).

Another important conceptual and methodological issue when measuring active accessibility is the scale of analysis. Our results show great disparity in values of travel impedance (distance or time). Therefore, scale effects (i.e., spatial resolution and spatial extent) are likely to be a major issue, as these two parameters are pre-determined in most methodologies and not normally subject to a sensitivity 
analysis. As already shown, however, differences in scales will produce significantly different results (Apparicio et al. 2008). Edge effects are also often overlooked, although some interesting methods having been presented to overcome this issue (Krizek 2003; Sadler, Gilliland, and Arku 2011). Nevertheless, despite these efforts the majority of studies do not assess, for instance, the impact of variation in the usual 400-meter (0.25-mile) buffer.

A final major issue in measuring active accessibility is that the vast majority of methods focus on origins and not destinations. We argue that the active accessibility conditions at destinations may be as important as those at the origin in explaining active travel behavior. We take the example of someone who lives in a highly accessible place but works in a car-dependent place. In this case, we argue that the features of the area around the destination, as expressed in the Behavioral Model of the Environment, will play a major role in explaining active travel. Therefore, we believe further research is needed to understand how these components of the model can be included in the calculation of active accessibility. We believe that space-time accessibility measures can provide a useful methodological framework to achieve this, due to their spatial and temporal restrictions.

Our review revealed that there is still a long way to go before there is a common definition and methodology to measure active accessibility. It may not even be possible as accessibility, which is a feature of the built environment, reflects its multidimensional and multi-scalar characteristics. Indeed, the existent diversity of metrics reflects the complexity of the accessibility concept. Each metric is somehow an imperfect instrument to measure a complex concept, each one focusing on some characteristics from a particular perspective. Having several methods cannot be considered negative, as it reveals the research efforts to measure complex and somehow elusive concepts, but it poses a risk of using the same concept to describe different aspects and perspectives of the same phenomenon. Nevertheless, here we suggest some ways to increase knowledge and reduce uncertainty. First, researchers must make the parameters they use clear, together with the assumptions used to define them; maximum travel distances and travel speeds are obvious examples. Second, concepts and expressions should be used carefully, they should be clearly defined, and the same concept should not be used with different meanings. Third, whenever a new methodology or a refinement to an existing methodology is presented, a sensitivity analysis should be carried out in order to evaluate the relevance of the new methodology, parameter or variable. Fourth, our research clearly shows that although walking accessibility has received a lot of attention in the literature, bicycle accessibility has received very little attention. The few studies that have been carried out have focused on an assessment of bike lane infrastructure (infrastructure-based measures). We argue that this is a major field for future research. Fifth, slope should be explicitly included as a measurement of active accessibility, due to the major influence it has on personal travel route choices. Sixth, active accessibility measures that are used as explanatory variables of active travel should include both origin- and destination-based indicators, as travel behavior probably also relates to walking and cycling conditions in areas around destinations. Individual-based accessibility measures can be extremely useful for this purpose. Finally, following Krizek (2003), an analysis of multicollinearity may be required when there are composite indices, and other statistical techniques such as factorial analysis would significantly improve measures.

\section{Acknowledgments}

We would like to acknowledge the financial support given to our project, the Integration of Land Use and Transport in Medium-Sized Cities (InLUT), by the Portuguese Funding Agency for Science,

Research and Technology (project reference PTDC/AUR-URB/111013/2009). We would also like to thank the two anonymous referees who provided useful insights on an earlier version of this paper. 


\section{References}

Abley, S., and A. Consultants. 2010. Measuring accessibility and providing transport choice. Australian Institute of Traffic Planning and Management (AITPM), National Conference, July 21-23, Brisbane, Australia.

Achuthan, K., H. Titheridge, and R. L. Mackett. 2007. Measuring pedestrian accessibility. Proceedings of the Geographical Information Science Research UK (GISRUK) Conference, National Center for Geocomputation, Maynooth, Ireland.

Achuthan, K., H. Titheridge, and R. L. Mackett. 2010. Mapping accessibility differences for the whole journey and for socially excluded groups of people. Journal of Maps 6: 220-229. doi: 10.4113/jom.2010.1077.

Alayo, J. 2001. Pedestrian accessibility and city form. Walk21, 3rd International Conference, May 9-10, Donostia, San Sebastian.

Allan, A. 2001. Walking as a local transport model choice in Adelaide. World Transport Policy and Practice 7: 44-51.

Apparicio, P., M. Abdelmajid, M. Riva, and R. Shearmur. 2008. Comparing alternative approaches to measuring the geographical accessibility of urban health services: Distance types and aggregationerror issues. International Journal of Health Geographics 7: pages. doi: 10.1186/1476-072X-7-7.

Apparicio, P., M.-S. Cloutier, and R. Shearmur. 2007. The case of Montréal's missing food deserts: Evaluation of accessibility to food supermarkets. International Journal of Health Geographics 6: pages. doi: 10.1186/1476-072X-6-4.

Aultman-Hall, L., M. Roorda, and B. W. Baetz. 1997. Using GIS for Evaluation of Neighborhood Pedestrian Accessibility. Journal of Urban Planning and Development 123: 10-17. doi: 10.1061/(ASCE)0733-9488(1997)123:1(10).

Bradshaw, C. 1993. Creating — and Using — a Rating System for Neighborhood Walkability. hearthhealth.wordpress.com/about/previously-published-works/feet-first-early/creaing-and-using-a-rating-system-for-neighbourhood-walkability-towards-an-agenda-for-local-heroes-1993/

Brewster, M., D. Hurtado, S. Olson, and J. Yen. 2009. Walkscore.com: A new methodology to explore associations between neighborhood resources, race, and health. https:/apha.confex.com/ recording/apha/137am/pdf/free/4db77adf5df9fff0d3caf5cafe28f496/paper205082_1.pdf

Brownson, R. C., C. M. Hoehner, K. Day, A. Forsyth, and J. F. Sallis. 2009. Measuring the built environment for physical activity: State of the science. American Journal of Preventive Medicine 36: S99-123.e12. doi: 10.1016/j.amepre.2009.01.005.

Carr, L. J., S. I. Dunsiger, and B. H. Marcus. 2010. Walk score ${ }^{\mathrm{TM}}$ as a global estimate of neighborhood walkability. American Journal of Preventive Medicine 39: 460-463. doi: 10.1016/j.amepre.2010.07.007.

Church, R. L., and J. R. Marston. 2003. Measuring accessibility for people with a disability. Geographical Analysis 35: 83-96. doi: 10.1111/j.1538-4632.2003.tb01102.x.

City of Portland. 1998. Portland Pedestrian Master Plan. Portland: Portland Office of Transportation. Clark, A., and D. Scott. 2013. Understanding the impact of the modifiable areal unit problem on the relationship between active travel and the built environment. Urban Studies 51(2): 1-16. doi: $10.1177 / 0042098013489742$.

Colclough, J. G. 2009. Modeling pedestrian accessibility using GIS techniques to assess development sustainability. European Transport Conference, Leiden Leeuwenhorst Conference Center, DATES, CITY, Netherlands.

Dannenberg, A. L., T. W. Cramer, and C. J. Gibson. 2005. Assessing the walkability of the workplace: A new audit tool. American Journal of Health Promotion 20: 39-44. doi: 10.4278/0890-1171-20.1.39. 
Dill, J. 2004. Measuring network connectivity for bicycling and walking. 83rd Annual Meeting of the Transportation Research Board, DATES, Washington, DC.

Dong, X., M. Ben-Akiva, J. L. Bowman, and J. L. Walker. 2006. Moving from trip-based to activitybased measures of accessibility. Transportation Research Part A 40(2): 163-180.

Duncan, D. T., J. Aldstadt, J. Whalen, S. J. Melly, and S. L. Gortmaker. 2011. Validation of walkscore for estimating neighborhood walkability: An analysis of four US metropolitan areas. International Journal of Environmental Research and Public Health 8: 4160-4179. doi: 10.3390/ijerph8114160.

El-Geneidy, A. M., and D. M. Levinson. 2006. Access to Destinations: Development of Accessibility Measures. Report \#1 in the series Access to Destinations Study. St. Paul, MN: Minnesota Department of Transportation.

El-Geneidy, A. M., and D. M. Levinson. 2011. Place rank: Valuing spatial interactions. Networks and Spatial Economics 11: 643-659. doi: 10.1007/s11067-011-9153-z.

Emery, J., and C. Crump. 2003. The WABSA Project: Assessing and Improving Your Community's Walkability and Bikeability. Chapel Hill, NC: Department of Health Behavior and Health Education School of Public Health,The University of North Carolina at Chapel Hill.

Ewing, R., and S. Handy. 2009. Measuring the unmeasurable: Urban design qualities related to walkability. Journal of Urban Design 14: 65-84. doi: 10.1080/13574800802451155.

Forsyth, A., M. Hearst, J. M. Oakes, and K. H. Schmitz. 2008. Design and destinations: Factors influencing walking and total physical activity. Urban Studies 45: 1973-1996. doi: $10.1177 / 0042098008093386$.

Forsyth, A., J. M. Oakes, K. H. Schmitz, and M. Hearst. 2007. Does residential density increase walking and other physical activity? Urban Studies 44: 679-697. doi: 10.1080/00420980601184729.

Forsyth, A., and M. Southworth. 2008. Guest editorial: Cities afoot—pedestrians, walkability and urban design. Journal of Urban Design 13: 1-3. doi: 10.1080/13574800701816896.

Frank, L. D., A. Devlin, S. Johnstone, and J. van Loon. 2010. Neighbourhood Design, Travel, and Health in Metro Vancouver: Using a Walkability Index. Vancouver: University of British Columbia.

Frank, L. D., J. F. Sallis, T. L. Conway, J. E. Chapman, B. E. Saelens, and W. Bachman. 2006. Many pathways from land use to health: Associations between neighborhood walkability and active transportation, body mass index, and air quality. Journal of the American Planning Association 72: 75-87. doi: 10.1080/01944360608976725.

Frank, L. D., T. L. Schmid, J. F. Sallis, J. Chapman, and B. E. Saelens. 2005. Linking objectively measured physical activity with objectively measured urban form: Findings from SMARTRAQ. American Journal of Preventive Medicine 28(2S2): 117-125.

Freeman, L., K. Neckerman, O. Schwartz-Soicher, J. Quinn, C. Richards, M. D. M. Bader, G. Lovasi, D. Jack, C. Weiss, K. Konty, P. Arno, D. Viola, B. Kerker, and A. G. Rundle. 2012. Neighborhood walkability and active travel (walking and cycling) in New York City. Journal of Urban Health: Bulletin of the New York Academy of Medicine 90: 575-585. doi: 10.1007/s11524-012-9758-7.

Gebel, K., A. E. Bauman, T. Sugiyama, and N. Owen. 2011. Mismatch between perceived and objectively assessed neighborhood walkability attributes: Prospective relationships with walking and weight gain. Health and Place 17: 519-524. doi: 10.1016/j.healthplace.2010.12.008.

Gerike, R., J. Gerlach, and A. Rau. 2009. Accessibility standards-Discussion of their necessity with the example of the German Guidelines for Integrated Network Design (RIN). 1st Transatlantic NECTAR Conference, June 18-20, Arlington, VA.

Geurs, K. T., and J. R. van Eck. 2001. Accessibility measures: Review and applications. RIVM report 408505006. Bilthoven, The Netherlands: RIVM, National Institute of Public Health and the Environment. rivm.nl/bibliotheek/rapporten/408505006.pdf). 
Geurs, K. T., and B. Van Wee. 2004. Accessibility evaluation of land-use and transport strategies: Review and research directions. Journal of Transport Geography 12(2): 127-140.

Giles-Corti, B., K. Boyer, G. Wood, T. Pikora, V. Learnihan, M. Bulsara, K. Van Niel, A. Timperio, G. McCormack, and K. Villanueva. 2011. School site and the potential to walk to school: The impact of street connectivity and traffic exposure in school neighborhoods. Health and Place 17: 545-550. doi: 10.1016/j.healthplace.2010.12.011.

Glazier, R. H., J. T. Weyman, M. I. Creatore, P. Gozdyra, R. Moineddin, F. I. Matheson, J. R. Dunn, and G. L. Booth. 2012. Development and Validation of an Urban Walkability Index for Toronto, Canada. Toronto: Toronto Community Health Profiles.

Halden, D., D. McGuigan, A. Nisbet, and A. McKinnon. 2000. Accessibility: Review of Measuring Techniques and Their Application. Edinburgh: Scottish Executive Central Research Unit.

Handy, S. 2005. Planning for accessibility: In theory and in practice. In Access to Destinations, edited by D. M. Levinson and K. J. Krizek, 131-147. Oxford: Elsevier.

Handy, S., and D. A. Niemeier. 1997. Measuring accessibility: An exploration of issues and alternatives. Environment and Planning A 29(7): 1175-1194. doi: 10.1068/a291175.

Handy, S., R. G. Paterson, and K. Butler. 2003. Planning for Street Connectivity: Getting from Here to There, Planning Advisory Service. Chicago: American Planning Association.

Handy, S. L., M. G. Boarnet, R. Ewing, and R. E. Killingsworth. 2002. How the built environment affects physical activity: Views from urban planning. American Journal of Preventive Medicine 23: 64-73. doi: 10.1016/S0749-3797(02)00475-0.

Handy, S. L., and K. J. Clifton. 2001. Evaluating neighborhood accessibility: Possibilities and practicalities. Journal of Transportation and Statistics 4: 67-78.

Hansen, W. G. 1959. How accessibility shapes land use. Journal of the American Institute of Planners 25(1): 73-76.

Harris, B. 2001. Accessibility: concepts and applications. Journal of Transportation and Statistics 4(2/3): $15-30$.

Hess, D. B. 2001. Effect of free parking on commuter mode choice: Evidence from travel diary data. Transportation Research Record 1753: 35-42.

Hillier, B. 1996. Cities as movement economies. Urban Design International 1: 41-60. doi: 10.1057/ udi.1996.5.

Hillier, B., and J. Hanson. 1984. The Social Logic of Space. Cambridge: Cambridge University Press.

Hirsch, J. A., K. A. Moore, K. R. Evenson, D. A. Rodriguez, and A. V. Diez Roux. 2013. Walk Score ${ }^{\bullet}$ and Transit Score ${ }^{\oplus}$ and walking in the multi-ethnic study of atherosclerosis. American Journal of Preventive Medicine 45: 158-166. doi: 10.1016/j.amepre.2013.03.018.

Hoedl, S., S. Titze, and P. Oja. 2010. The bikeability and walkability evaluation table: Reliability and application. American Journal of Preventive Medicine 39: 457-459. doi: 10.1016/j.amepre.2010.07.005.

Horacek, T. M., A. A. White, G. W. Greene, M. M. Reznar, V. M. Quick, J. S. Morrell, S. M. Colby, K. K. Kattelmann, M. S. Herrick, K. P. Shelnutt, A. Mathews, B. W. Phillips, and C. ByrdBredbenner. 2012. Sneakers and spokes: An assessment of the walkability and bikeability of US postsecondary institutions. Journal of Environmental Health 74: 8-15.

Horner, M. W. 2004. Exploring metropolitan accessibility and urban structure. Urban Geography 25(3): 264-284.

Hull, A., C. Silva, and L. Bertolini. 2012. COST Action TU1002-Accessibility Instruments for Planning Practice. Brussels: COST Office.

Iacono, M., K. J. Krizek, and A. El-Geneidy. 2010. Measuring non-motorized accessibility: Issues, alternatives, and execution. Journal of Transport Geography 18(1): 133-140. 
Kim, H.-M., and M.-P. Kwan. 2003. Space-time accessibility measures: A geocomputational algorithm with a focus on the feasible opportunity set and possible activity duration. Journal of Geographical Systems 5: 71-91. doi: 10.1007/s101090300104.

Kockelman, K. 1997. Travel behavior as a function of accessibility, land use mixing, and land use balance: Evidence from the San Francisco Bay Area. Transportation Research Record 1607: 117-125.

Krizek, K. J. 2003. Operationalizing neighborhood accessibility for land use-travel behavior research and regional modeling. Journal of Planning Education and Research 2 (3): 270-287.

Kwan, M.-P. 1998. Space-time and integral measures of individual accessibility: A comparative analysis using a point-based framework. Geographical Analysis 30(3): 191-216.

Kwan, M.-P., and J. Weber. 2003. Individual accessibility revisited: Implications for geographical analysis in the twenty-first century. Geographical Analysis 35(4): 341-353.

Le Vine, S., M. Lee-Gosselin, A. Sivakumar, and J. Polak. 2013. A new concept of accessibility to personal activities: Development of theory and application to an empirical study of mobility resource holdings. Journal of Transport Geography 31: 1-10. doi: 10.1016/j.jtrangeo.2013.04.013.

Lee, C., and A. V. Moudon. 2004. Physical activity and environment research in the health field: Implications for urban and transportation planning practice and research. Journal of Planning Literature 19: 147-181. doi: 10.1177/0885412204267680.

Lee, C., and A. V. Moudon. 2006. The 3Ds+R: Quantifying land use and urban form correlates of walking. Transportation Research Part D 11: 204-215. doi: 10.1016/j.trd.2006.02.003.

Lemon, J. C. 2010. Using Geographic Information Systems to measure walkability in Cincinnati, Ohio. $\mathrm{MsC}$ dissertation, University of Cincinnati.

Leslie, E., I. Butterworth, and M. Edwards. 2006. Measuring the walkability of local communities using Geographic Information Systems data. Walk21-VII, The Next Steps, The 7th International Conference on Walking and Liveable Communities, October 23-25, Melbourne.

Leslie, E., N. Coffee, L. D. Frank, N. Owen, A. Bauman, and G. Hugo. 2007. Walkability of local communities: Using geographic information systems to objectively assess relevant environmental attributes. Health and Place 13: 111-22. doi: 10.1016/j.healthplace.2005.11.001.

Lowry, M., and D. Callister. 2012. Using bicycle level of service to assess community-wide bikeability. 91st Annual Meeting of the Transportation Research Board, January 22-26, Washington, DC.

Lundberg, B. 2012. Accessibility and university populations: Local effects on non-motorized transportation in the Tuscaloosa-Northport area. MsC dssertation. University of Alabama, CITY.

Lwin, K. K., and Y. Murayama. 2011. Modeling of urban green space walkability: Eco-friendly walk score calculator. Computers, Environment and Urban Systems 35: 408-420. doi: 10.1016/j.compenvurbsys.2011.05.002.

Maghelal, P. K., and C. J. Capp. 2011. Walkability: A Review of existing pedestrian indices. URISA Journal 23: 5-19.

Manaugh, K., and A. El-Geneidy. 2011. Validating walkability indices: How do different households respond to the walkability of their neighborhood? Transportation Research Part D 16: 309-315. doi: $10.1016 /$ j.trd.2011.01.009.

Manaugh, K., and A. El-Geneidy. 2012. What makes travel local: Defining and understanding local travel behavior. Journal of Transport and Land Use 5: 15-27. doi: 10.5198/jtlu.v5i3.300.

Mantri, A. 2008. A GIS based approach to measure walkability of a neighborhood. MsC dissertation, University of Cincinnati.

Mavoa, S., K. Witten, T. McCreanor, and D. O’Sullivan. 2012. GIS based destination accessibility via public transit and walking in Auckland, New Zealand. Journal of Transport Geography 20(1): $15-22$. 
McNeil, N. 2011. Bikeability and the 20-min neighborhood: How infrastructure and destinations influence bicycle accessibility. Transportation Research Record 2247: 53-63. doi: 10.3141/2247-07.

Miller, H. J. 1999. Measuring space-time accessibility benefits within transportation networks: Basic theory and computational procedures. Geographical Analysis 31:1-26. doi: 10.1111/j.1538-4632.1999.tb00408.x.

Miller, H. J. 2005. Place-based versus people-based accessibility. In Access to Destinations, edited by D. M. Levinson and K. J. Krizek, 63-89. Oxford: Elsevier.

Miller, H. J. 2007. Place-based versus people-based geographic information science. Geography Compass 1(3): 503-535.

Miller, H. J., and Y.-H. Wu. 2000. GIS software for measuring space-time accessibility in transportation planning and analysis. GeoInformatica 4: 141-159. doi: 10.1023/A:1009820006075.

Moudon, A. V., and C. Lee. 2003. Walking and bicycling: An evaluation of environmental audit instruments. American Journal of Health Promotion 18: 21 -37 . doi: 10.4278/0890-1171-18.1.21.

Munoz, U. H., and C. Källestål. 2012. Geographical accessibility and spatial coverage modeling of the primary health care network in the Western Province of Rwanda. International Journal of Health Geographics 11: 40. doi: 10.1186/1476-072X-11-40.

Nikolaos, E., G. Athanasios, and P. Apostolos. 2009. Evaluation of the bikeability of a Greek city: Case study City of Volos. WSEAS Transactions on Environment and Development 5: 149-152.

Páez, A., D. M. Scott, and C. Morency. 2012. Measuring accessibility: Positive and normative implementations of various accessibility indicators. Journal of Transport Geography 25: 141-153. doi: 10.1016/j.jtrangeo.2012.03.016.

Pearce, J., K. Witten, and P. Bartie. 2006. Neighborhoods and health: A GIS approach to measuring community resource accessibility. Journal of Epidemiology and Community Health 60: 389-95. doi: 10.1136/jech.2005.043281.

Pikora, T., B. Giles-Corti, F. Bull, K. Jamrozik, and R. Donovan. 2003. Developing a framework for assessment of the environmental determinants of walking and cycling. Social Science and Medicine 56: 1693-1703. doi: 10.1016/S0277-9536(02)00163-6.

Rodrigue, J.-P., C. Comtois, and B. Slack. 2013. The Geography of Transport Systems. 3rd ed. New York: Routledge.

Sadler, R. C., J. A. Gilliland, and G. Arku. 2011. An application of the edge effect in measuring accessibility to multiple food retailer types in southwestern Ontario, Canada. International Journal of Health Geographics 10(34): 1-14. doi: 10.1186/1476-072X-10-34.

Saelens, B. E., and S. L. Handy. 2008. Built environment correlates of walking: A review. Medicine and Science in Sports and Exercise 40: S550-66. doi: 10.1249/MSS.0b013e31817c67a4.

Saelens, B. E., J. F. Sallis, and L. D. Frank. 2003. Environmental correlates of walking and cycling: Findings from the transportation, urban design, and planning literatures. Annals of Behavioral Medicine 25(2): 80-91. doi: 10.1207/S15324796ABM2502_03.

Sakkas, N., J. Pérez, C. Lemmen, and P. van Oosterom. 2006. Elaborating metrics for the accessibility of buildings. Computers, Environment and Urban Systems 30: 661-685. doi: 10.1016/j.compenvurbsys.2005.06.002.

Shen, G. 2002. Measuring accessibility of housing to public-community facilities using Geographical Information Systems. Review of Urban and Regional Development Studies 14: 235-255. doi: 10.1111/1467-940X.00056.

Silva, C., and P. Pinho. 2010. The Structural Accessibility Layer (SAL): Revealing how urban structure constrains travel choice. Environment and Planning A 42: 2735-2752. doi: 10.1068/a42477. 
Sisson, S. B., S. M. Lee, E. K. Burns, and C. Tudor-Locke. 2006. Suitability of commuting by bicycle to Arizona elementary schools. American Journal of Health Promotion 20: 210-213. doi: 10.4278/0890-1171-20.3.210.

Ståhle, A., L. Marcus, and A. Karlström. 2005. Place syntax-Geographic accessibility with axial lines in GIS. Proceedings from Fifth International Space Syntax Symposium, June 13-17, Delft.

Straatemeier, T., and L. Bertolini. 2008. Joint accessibility design: Framework developed with practitioners to integrate land use and transport planning in the Netherlands. Transportation Research Record 2077: 1-8. doi: 10.3141/2077-01.

Sun, G., H. Lin, and R. Li. 2012. Measuring the influence of built environment on walking behavior: An accessibility approach. Geographic Information Science 7478: 187-197. doi: 10.1007/978-3642-33024-7_14.

Talen, E. 2003. Measuring urbanism: Issues in smart growth research. Journal of Urban Design 8: 195-215. doi: 10.1080/1357480032000155141.

Talen, E., and J. Koschinsky. 2013. The walkable neighborhood: A literature review. International Journal of Sustainable Land Use and Urban Planning 1: 42־-63.

Tobler, W. R. 1970. A computer movie simulating urban growth in the Detroit region. Economic Geography 46: 234-240. doi: 10.2307/143141.

Vale, D. S. 2010. Sustainable Urban Form, Accessibility and Travel: The Relationship Between Polycentric Urban Development and Commuting in Lisbon. Saarbrücken, Germany: Lambert Academic Publishing.

Vale, D. S. 2013. Does commuting time tolerance impede sustainable urban mobility? Analyzing the impacts on commuting behaviour as a result of workplace relocation to a mixed-use centwe in Lisbon. Journal of Transport Geography 32 (1): 38-48. doi: 10.1016/j.jtrangeo.2013.08.003.

Van Dyck, D., G. Cardon, B. Deforche, J. F. Sallis, N. Owen, and I. De Bourdeaudhuij. 2010. Neighborhood SES and walkability are related to physical activity behavior in Belgian adults. Preventive Medicine 50 Suppl 1: S74-S79. doi: 10.1016/j.ypmed.2009.07.027.

Van Eggermond, M., and M. Erath. 2014. Pedestrian and transit accessibility on a micro-level: Results and challenges. World Symposium for Transport and Land Use Research 2014, DATES, Delft, Netherlands. Url: wstlur.org/symposium/2014/presentations/vanEggermond_Erath.pdf.

Vargo, J., B. Stone, and K. Glanz. 2012. Google walkability: A new tool for local planning and public health research? Journal of Physical Activity and Health 9: 689-697.

Vasconcelos, A. S., and T. L. Farias. 2012. Evaluation of urban accessibility indicators based on internal and external environmental costs. Transportation Research Part D 17: 433-441. doi: 10.1016/j. trd.2012.05.004.

Winters, M., M. Brauer, E. M. Setton, and K. Teschke. 2013. Mapping bikeability: A spatial tool to support sustainable travel. Environment and Planning B 40(5): 865-883.

Yigitcanlar, T., N. Sipe, R. Evans, and M. Pitot. 2007. A GIS-based land use and public transport accessibility indexing model. Australian Planner 44: 30-37. doi: 10.1080/07293682.2007.9982586.

Zhao, F., L.-F. Chow, M.-T. Li, I. Ubaka, and A. Gan. 2003. Forecasting transit walk accessibility: Regression model alternative to buffer method. Transportation Research Record 1835: 34-41. doi: 10.3141/1835-05.

Zielstra, D., and H. H. Hochmair. 2011. Comparative study of pedestrian accessibility to transit stations using free and proprietary network data. Transportation Research Record 2217: 145-152. doi: $10.3141 / 2217-18$. 